\title{
Electrical Resistivity of Some Basalt and Granite Samples From Egypt
}

\author{
M. S. Mostafa, N. Afify A. Gaber and E. F. Abozid*, \\ Physics Department, Faculty of Science, Assiut University, Assiut
}

In this paper we studied the temperature dependence of the electrical resistivity of basalt and granite samples. The electrical resistivity of these samples were measured in the temperature range from RT to $1000 \mathrm{~K}$. It is observed that, The electrical resistivity of all investigated samples was decreased with the increase of temperature. The results showed that, the behaviour of the electrical resistivity have two conduction regions for basalt and granite samples. In the first region (RT to $400 \mathrm{~K}$ ) for basalt and $(R T-450 \mathrm{~K})$ for granite samples, the electrical resistivity exhibits a slight decrease. In the second region (400 to $1000 \mathrm{~K})$ for basalt and (450 to $1000 \mathrm{~K}$ ) for granite samples, the electrical resistivity exhibit a rapid decrease with the increase of temperature. The average activation energies of investigated basalt and granite samples are calculated and discussed.

\section{Introduction:}

Considerably little is known about the electrical resistivity of crystalline rocks like basalt and granite particularly under conditions likely to prevail at deeper levels in the crust[1]. Few observations have been reported on the effects of elevated temperatures and pressure on the resistivity of dry rocks. The major problem, which faces the interpretation of the electrical resistivity models in the earth, is the acknowledged discrepancy between field and laboratory determinations. Resistivities determined in the field by magnetotellurics (MT) or by other resistivity methods are, with volumetrically rare exceptions, much higher than those obtained in ordinary dry laboratory specimens of crustal and mantel rocks, [2]. The electrical resistivity of the mantel of the earth has been estimated by several methods, as summarized by $[3,4]$. A comparison of these resistivity results on possible mantel constituents might yield further information about the temperature, composition, or conduction mechanisms in the mantel. There is a direct association of electrical resistivity with 
temperature. This is observed in the field of correlation of resistivity with heat flow, [5-8]. It is well documented in the laboratory that the equation:

$$
\rho=\rho_{0} \exp \left(E / k_{B} T\right)
$$

applies to nearly all minerals. Here $\boldsymbol{\rho}$ is electrical resistivity (usually expressed in ohm. $\mathrm{cm}$ ), $\rho_{\mathbf{0}}$ is pre-exponential factor, $\mathbf{k}_{\mathbf{B}}$ is the Boltzmann constant, $\mathbf{T}$ absolute temperature and $\mathbf{E}$ the activation energy in $\mathrm{eV}$. Consistent results were reported for basalt and granite samples by [9]. They cited that solid samples of basalt and granite were better conductors than the same rock samples in powdered form. In their study, DC conductivity was 4.5 to 5 orders of magnitude higher for basalt and 2 to 4 orders of magnitudes higher for granite in a temperature range from 373 to $772 \mathrm{~K}$. In comparison between these measurements which were done in vacuum there were that, the higher conductivity of the solid samples than of the powdered ones was attributed to better contacts between crystals in the solid samples than in the powdered samples. The mineral composition, $\mathrm{x}$-ray fluorescence analysis (XRF) and rock structure are found in $[10,11]$.

\section{Experimental work:}

The investigated bulk samples in our work were obtained from different regions of the Eastern Desert of Egypt [10,11].

The bulk samples were cut into disks by means of an impregnated diamond-slitting disk. The sample faces were polished and lapped parallel. The samples prepared in the shape of disk 25- $\mathrm{mm}$ diameter and 6-8 $\mathrm{mm}$ thickness to be most suitable for the electrical properties investigation. The electrical resistivity measurements were carried out using the circuit, [11].

\section{Results and Discussion:}

A typical temperature dependence of the electrical resistivity of basalt specimens in the temperature range from 300 to $1000 \mathrm{~K}$ is shown in Fig. (1- $\mathrm{B}_{1}$ ) which shows two regions. The first region lies in the range from room temperature up to $400 \mathrm{~K}$ and the second region lies in the range from 400 to $1000 \mathrm{~K}$. This result indicated that there are two conduction mechanisms. From the linear fitting of the Arrhenius relation between the electrical resistivity and the reciprocal of temperature, the activation energy of these specimens can be obtained. 


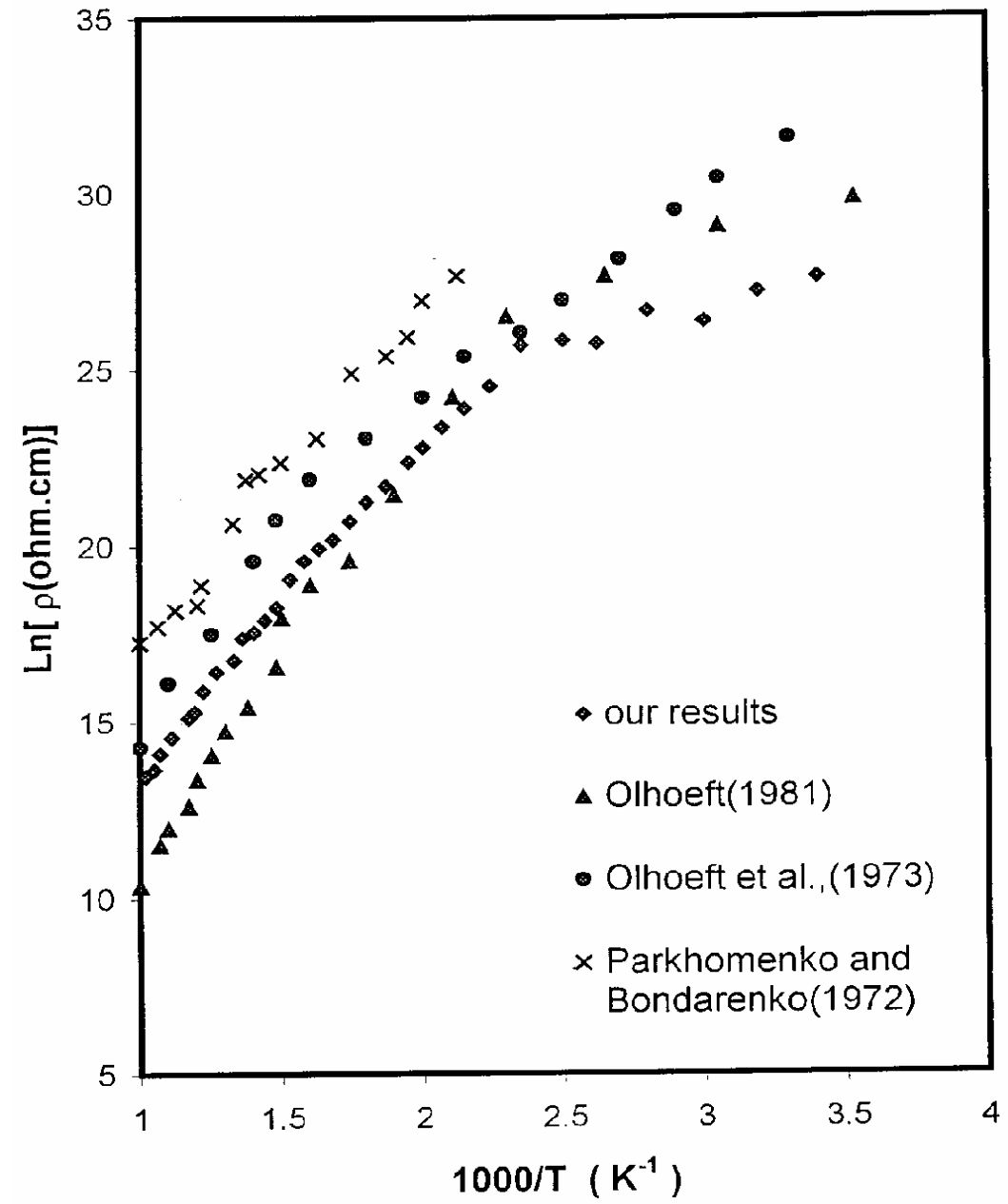

Fig.(1): A typical Temperature dependence of the measured electrical resistivity of Basalt samples $\left(\mathrm{B}_{1}\right)$.

It is obvious that the two regions (RT-400 K and 400-1000 K) for basalt samples exhibit straight lines. From the slopes, the activation energies of the conduction mechanisms are calculated and tabulated in Table (1).

For the investigated granite samples all curves have also two regions, asimilar behaviour as basalt samples is observed with the exception that granite specimens show two conduction mechanisms laying in the range RT to $450 \mathrm{~K}$ and 450 to $1000 \mathrm{~K}$, Fig. $\left(2-\mathrm{G}_{1}\right)$. From the fitting of the Arrhenius relations for granite (RT-450 K and 450-1000 K) the activation energies of the mechanisms are also shown in Table (1). 


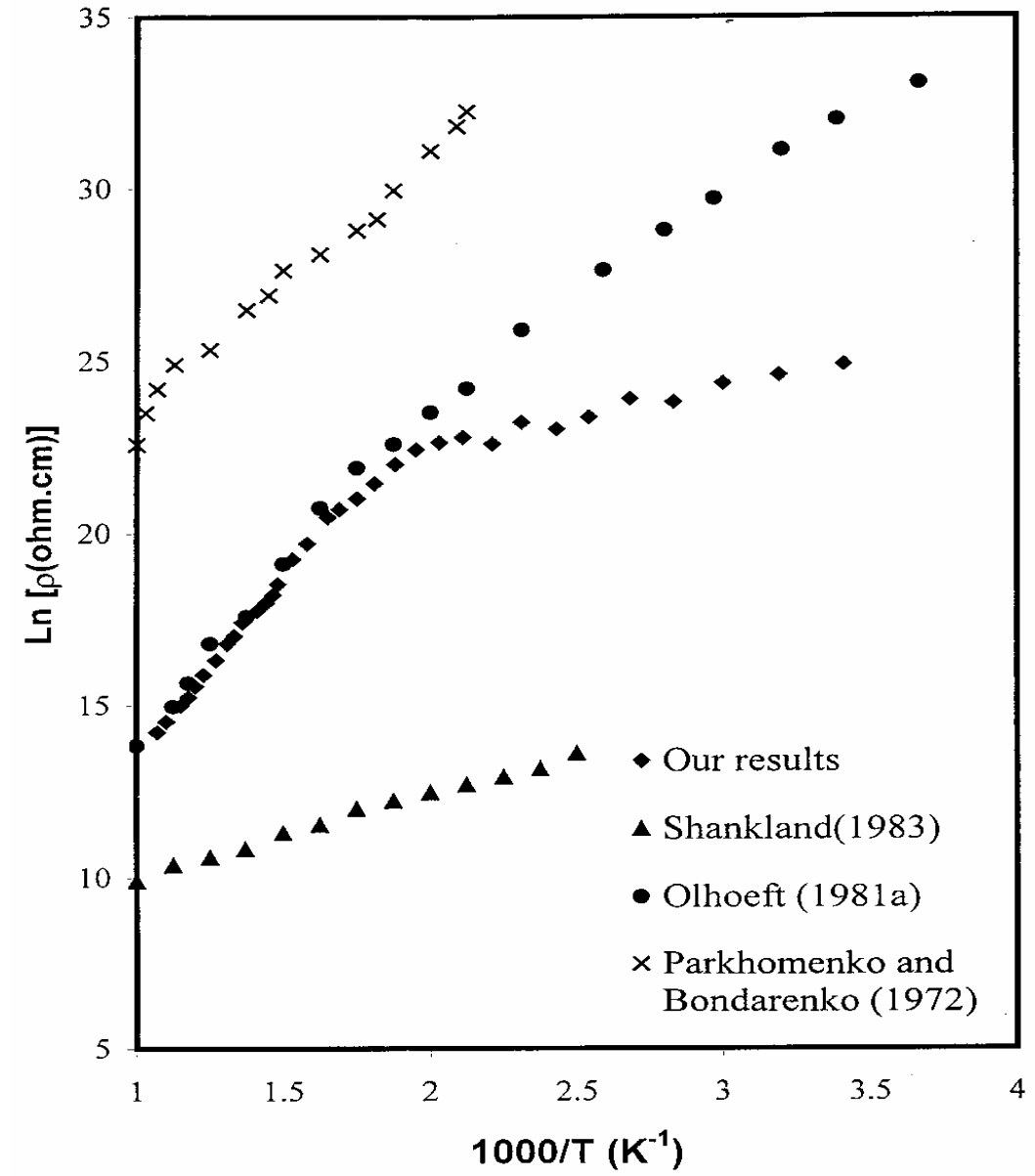

Fig.(2): A typical Temperature dependence of the measured electrical resistivity of Granite samples $\left(\mathrm{G}_{1}\right)$.

Table (1): The activation energies of the investigated samples. ( $E_{1}$ and $E_{2}$ are the activation energies for the first and second regions, respectively).

\begin{tabular}{|c|l|l|l|l|}
\hline Sample & $\mathrm{E}_{1}(\mathrm{eV})$ & $\mathrm{E}_{2}(\mathrm{eV})$ & $<\mathrm{E}_{1}>(\mathrm{eV})$ & $<\mathrm{E}_{2}>(\mathrm{eV})$ \\
\hline $\mathrm{B}_{1}$ & 0.273 & 0.834 & & \\
$\mathrm{~B}_{2}$ & 0.093 & 0.706 & $\{0.152\}$ & $\{0.930\}$ \\
$\mathrm{B}_{3}$ & 0.107 & 1.203 & & \\
$\mathrm{~B}_{4}$ & 0.137 & 0.979 & & \\
\hline $\mathrm{G}_{1}$ & 0.152 & 0.837 & & \\
$\mathrm{G}_{2}$ & 0.148 & 1.120 & & \\
$\mathrm{G}_{3}$ & 0.126 & 0.473 & $\{0.140\}$ & $\{0.761\}$ \\
$\mathrm{G}_{4}$ & 0.134 & 0.616 & & \\
\hline
\end{tabular}


The average of the activation energies of basalt is slightly higher than that of granite in the first and second regions. The average literature activation energies of basalt and granite in the whole range of temperature are 0.437 and $0.372 \mathrm{eV}$, respectively, [12-16]. Our results of activation energies are in agreement, because the behaviour of resistivity versus temperature exhibits two different conduction mechanisms. The small values of activation energy of these rocks may be attributed to the contribution of ionic conduction. It is worthy to mention that, these values are in the range of semiconducting materials and minerals, [17]. It is obvious that, electrical resistivity is the sum of two several thermally activated processes described by exponential curves

$$
\rho=\rho_{1} \exp \left(E_{1} / k_{B} T\right)+\rho_{2} \exp \left(E_{2} / k_{B} T\right)
$$

where $\mathbf{T}$ is the absolute temperature; $\mathbf{K}_{\mathbf{B}}$ is the Boltzmann constant, and $\mathbf{E}_{\mathbf{1}}, \mathbf{E}_{\mathbf{2}}$ are the activation energies in joule of the first and second regions respectively. The strong temperature dependence means that one conduction process usually dominates at a given temperature. However, because of the indications that two conduction mechanisms operate in the temperature range 300 to $1000 \mathrm{~K}$, the Published data indicate that, at higher temperatures in many materials the type of charge carrier changes, [18]. At high temperatures, charge carriers, which require very high activation energies become important. The changes in slope of these curves indicate that the type of charge carriers changes as the temperature is increased. Usually, impurity ions provide the charge carriers. The binding energy of impurity ions is somewhat less than the binding energy of regular lattice ions and, as a result, they are available for conduction at lower temperatures.

If a phase change takes place, there is an abrupt discontinuity in the, $\mathrm{Ln}$ $\rho=\mathbf{f}(\mathbf{1} / \mathbf{T})$ curve, as shown in figures $(1,2)$, the discontinuity in the curves of all basalt samples at a temperature of $400 \mathrm{~K}$ may be attributed to the release of combined water from the sample. From thermogravemetric analysis (TGA) $[10,11]$ it is found that in the beginning of the temperature rise a very small weight loss is recorded in the curves, which is ascribed to the evolution of the few percentage of free water from the samples. As the temperature increases the structurally bound water start to release from the samples at about $400 \mathrm{~K}$ which leads to the weight loss of the samples. In the first region of all curves the electrical resistivity decreases slightly with increasing temperature which may be attributed to that the only conduction mechanism is the impurity ions in the sample [16]. In the second region the electrical resistivity decreases rapidly with increasing temperature, which may be attributed to, the structural change can be taken place at high temperatures, [16], which enhances the electrical conductivity (decreases the electrical resistivity). The same results are shown for the granite samples with the only difference that the start of discontinuity in the curves occurred at a temperature of $\sim 450 \mathrm{~K}$. The electrical resistivity of basalt 
samples is lower than that of granite samples, this behaviour could be attributed to that, the investigated basalt samples are fine-grained samples, which have a lower electrical resistivity than the coarse-grained granite samples.

It is shown in figure (1) that in the temperature range from 300 to $400 \mathrm{~K}$ there is a small difference between the electrical resistivity of our results of basalt group and some published results, [18-20] which may be attributed to the difference in chemical composition and type of texture. In the temperature range from 400 to $1000 \mathrm{~K}$ there is an agreement between our results of basalt group and other groups of basalt which may be attributed to that, as the temperature increases, the major charge carriers in this temperature range are the lattice ions which may have the same effect on the electrical resistivity in all igneous rocks.

The X-ray chart after the electrical resistivity measurement show some peaks with small changes in their position and are more pronounced than those obtained before electrical measurements, $[10,11]$. This may be attributed to the oxidation and firing of some minerals during thermal treatment. Heat treatment means the effect on chemical composition after and before measurements. This means that, the heat treatment does not largely affect the electrical resistivity [10]. In measuring the temperature dependence of the electrical resistivity in a dielectric crystal, one should keep in mind the possibility of irreversible reactions, either mechanical or chemical taking at high temperatures. As discussed above, these ions or even at stable laboratory conditions are not readily attained. However, there are sufficiently strong correlation to establish the reality of differences between rocks of different compositions and texture despite a variety of experimental problems. The distinction between fine-grained and coarse-grained rocks is strong. The lower resistivity of basalt (fine-grained) group than granite (coarse-grained) group would come from additional surface conduction, the presence of glass phases, or both. The work of, [21] on powdered samples did show a clear decrease of conductivity with silica content. Our results of XRF for basalt and granite, $[10,11]$ are in fair agreement with this work. Thus the difference between basalt samples with each other in one hand in the silica content and with granite samples in the other hand makes the electrical resistivity differing in magnitudes from sample to the other in basalt group. Also the decrease of the silica content in basalt samples than in granite samples, $[10,11]$ makes the electrical resistivity of basalt group samples lower than that of granite group samples.

This result agrees with these of, [16] in their comprehensive report of rocks at high temperatures and pressures in relation to geoelectric and geothermal studies. Wanamaker [22] argued for the following trends:

(1) That a phanitic rock will have higher conductivities than their phaneritic (compositional) equivalents by one or two orders of magnitude because of 
the smaller activation energies for glassy and fine-grained components than for crystalline materials;

(2) That an increase in conductivity is observed with an increase in mafic constituents in a granite group. The accompanying increase in total content of $\mathrm{Fe}_{2} \mathrm{O}_{3}, \mathrm{FeO}$, and $\mathrm{CaO}$ was thought to be partially responsible for this effect. In our compilation for basaltic compositions, a phanitic rocks show a statistically significant higher conductivity by almost an order of magnitude than phaneritic rocks of the same composition at high temperature. They also note a statistically significant difference of the same order between the conductivities of less conductive silicic rocks and more conductive mafic rocks, [23].

\section{Conclusions:}

From the above discussion it can be concluded that:

(1) The relationship between natural logarithm of the electrical resistivity and the reciprocal of temperature of all investigated samples indicated that there are two conduction mechanisms. The first mechanism took place in the temperature range $(300-400 \mathrm{~K})$ for basalt samples and $(300-450 \mathrm{~K})$ for granite samples. The conduction mechanism is performed by impurity ions. The average activation energies associated with this mechanism are 0.152 $\mathrm{eV}$ for basalt and $0.140 \mathrm{eV}$ for granite samples. The second mechanism lies in the temperature range $(400-1000 \mathrm{~K})$ for basalt samples and $(450-1000 \mathrm{~K})$ for granite samples. The average activation energies associated with this conduction mechanism are higher, e. g. $0.930 \mathrm{eV}$ for basalt samples and $0.761 \mathrm{eV}$ for granite samples.

(2) The fine-grained structure of basalt samples has lower resistivity than coarse-grained structure of granite samples.

\section{References:}

1. U.Seipold, Techonophysics, 291, 161 (1998).

2. T. J. Shankland, and M. E. Ander, Journal of Geophysical Research, 88, B11, 9475 (1983).

3. D. C. Tozar, Phys. Chem. Earth, 3, 414 (1959).

4. H. G. Fournier, S. H. Ward, and H. F. Morrison, Tech. Rept. on Nonr 222(89), Ser. 4, Space Science Laboratory, University of California, 13 (1963).

5. A. Adam, Phys. Earth Planet. Inter., 17, 21 (1978).

6. A. Adam, Geophys. Surv, 4, 43 (1980). 
7. M. E. Ander, "Geophysical study of the crust and upper mantle beneath the central Rio Grande rift and adjacent Great Plains and Colorado Plateau", Tech. Rept. LA - 8676-T, Los Alamos Natl. Lab., Los Alamos, N. Mex., Dec. 218 (1980).

8. A. Kaufman, and G. R. Keller, "The Magnetotelluric Sounding Method", Elsevier, New York, 595 (1981).

9. M. Saint-Amant, and D. W. Strangway, Geophysics, 35, 4, 624 (1970).

10. M. S. Mostafa, N. Afify, A. Gaber, and E. F. Abu Zaid,, JTAC, accepted (2003).

11. E. F. Abu Zaid (Msc) thesis, Assiut University, Faculty of Scince, Assiut, Egypt, (2001).

12. H. P. Coster, Astron. Soc. Geophys. Supplement 5, 6,193 (1948).

13. K. Noritomi, J. Min. Coll., Akita Univ., Ser. A, 1, N9, 127 (1961).

14. Z. Hashin, and S. Shtrikman, J. Appl. Phys., 33, 3125 (1962).

14. T. Katsura, K. Sato, and E. Ito, Nature, 395, 493 (1998).

16. K. A. Kariya, and T. J. Shankland, Geophysics, 48, 1, 52 (1983).

17. C. Rai, and M. Manghnani, J. Geophys. Res. Astron. Soc., 65, 395 (1981).

18. E. I. Parkhomenko, "Electrical properties of rocks", a Volume in Monographs in Geoscience, Keller, G. V., Ed. (Plenum Press, New York, 1972).

19. M. P. Volarovich, and E. I. Parkhomenko, "Electrical properties of rocks at high temperatures and pressures", in Geoelectrical and Geothermal studies (East Central Europe, Sovite Asia), A. Adam, Ed. (Akademia Kiado, Budapest, 319,(1976)).

20. G. R. Olhoeft, J. Geophys. Res., 80, B2, 931 (1981).

21. R. Alvarez, J. P.Reynoso, L. J. Alvarez, and M. L. Martinez, Bull. Volcanol, 41, 4317 (1978).

22. B. J. Wanamaker, Geophys. Res. Lett., 20, 21 (1994).

23. G. R. Olhoeft, D. W. Strngway, and A. L. Frisillo, Geochim. Cosmochim. Acta Supl., 4, 3133 (1973). 